\title{
A CASE OF CONGENITAL DIABETES
}

\author{
BY \\ MARY E. S. WYLIE \\ From the Department of Child Health, University of Glasgow, and the Royal Hospital for Sick Children, Glasgon.
}

(RECEIVED FOR PUBLICATION MARCH 29, 1953)

Diabetes mellitis is relatively rare in infancy although it was diagnosed in an infant in 1789 . Schwartzmann, Crusius and Beirne (1947) reviewed 57 cases with the onset of symptoms in the first year of life. In 1952 Brodribb, McMurray and Scott reported two further cases.

During the first four weeks of life diabetes has been diagnosed on seven occasions, although the diagnostic criteria are open to doubt in some of the cases. The first was described by Kitselle (1852) in his own son who shortly after birth showed polyuria, polydipsia, emaciation and glycosuria, and who died after a few months. The second, recorded in 1910 by Cuno, was in a 15-day-old baby with glycosuria and hyperglycaemia. Necropsy showed atrophy of the pancreas. Ramsey, in 1926, reported the case of a 4-week-old premature baby presenting with excessive appetite and thirst, glycosuria and hyperglycaemia who appeared to recover completely in six weeks. Four years later this child had a normal glucose tolerance curve. Lawrence and McCance (1931) reported the case of an 18-day-old baby with gangrene of the leg who had glycosuria and a blood sugar level of $600 \mathrm{mg}$. per $100 \mathrm{ml}$. At 6 weeks of age this child appeared to recover spontaneously. Two cases have been recorded in Negro infants. Lewis and Eisenberg (1935) reported the case of a baby who had otitis media and bullous impetigo and was found to have glycosuria and a blood sugar level which varied between 280 and $520 \mathrm{mg}$. per $100 \mathrm{ml}$. Limper and Miller (1935) reviewed the case of a child with gangrene of the leg, glycosuria and a blood sugar level of $952 \mathrm{mg}$. per $100 \mathrm{ml}$. Neither of these infants survived long, in spite of insulin therapy. Atrophy of the pancreas was present in both cases. From this hospital in 1938 Devine described a 25-day-old premature baby who failed to thrive and on admission was found to have glycosuria and a blood sugar level of $542 \mathrm{mg}$. per $100 \mathrm{ml}$. The patient died before treatment could be instituted.

\section{Case Report}

A girl, aged 17 days, was admitted to hospital from a maternity home on May 15, 1952, because of failure to thrive in spite of feeds adequate in calories, which were taken eagerly. The provisional diagnosis was fibrocystic disease of the pancreas.

She was the first born child of young healthy parents from whom no history of familial diabetes or consanguinity could be obtained. The pregnancy was uncomplicated and the delivery normal but, though born at full term, the infant's birth weight was only $2.4 \mathrm{~kg}$, ( $5 \mathrm{lb}$. $5 \mathrm{oz}$.). The baby's condition immediately after birth gave no anxiety. At first she was reluctant to fix on the breast so she was fed with expressed breast milk. After a few days she sucked well but, despite a voracious appetite and the absence of any vomiting or diarrhoea, she steadily lost weight. On the assumption that she had a subclinical infection she was given a course of aureomycin without any improvement.

On admission to hospital the baby weighed $1.765 \mathrm{~kg}$. ( $3 \mathrm{lb} .14 \mathrm{oz}$ ) and presented a remarkable appearance of senility (Fig. 1).

There was gross emaciation and dehydration, the face was wrinkled and wizened, the fontanelle was sunken and the skull sutures were overriding. There was no evidence of infection. The liver edge was palpable one fingerbreadth below the costal margin, and the lower poles of both kidneys and the spleen were just palpable. There were no clinical signs of ketosis and, despite her

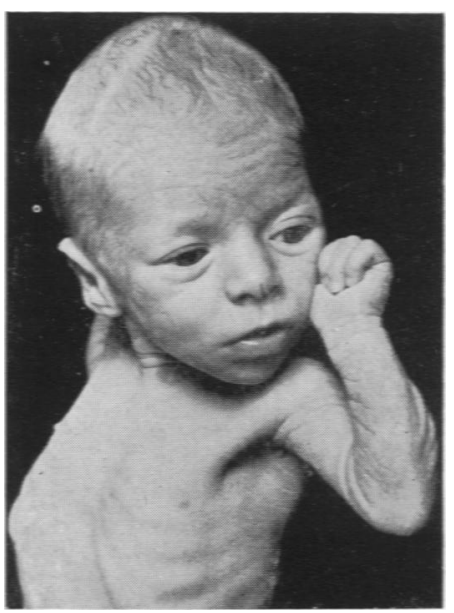

Fig. 1.-Appearance on admission to hospital at the age of 17 days. very poor general

condition, the baby was surprisingly alert, crying quite vigorously and eager to suck. Retinoscopy and electrocardiography did not reveal any abnormality.

The urine contained a trace of albumin, completely reduced Benedict's reagent, but did not contain ketones. The blood sugar level was $666 \mathrm{mg}$. per $100 \mathrm{ml}$. The blood 
galactose level was normal and only glucosazone crystals were recovered from the urine.

Ten units of soluble insulin were given intramuscularly and two hours later the blood sugar level was $708 \mathrm{mg}$. per $100 \mathrm{ml}$. After two further doses, each of 10 units, the blood sugar level had fallen to $102 \mathrm{mg}$. per $100 \mathrm{ml}$. 16 hours after admission. After the start of insulin therapy the baby stopped sucking and feeds (half-cream National Dried Milk, $60 \mathrm{ml}$., plus sugar, $5 \mathrm{~g}$., four-hourly) had to be given by tube. An intravenous infusion of quarter strength physiological saline with $5^{\circ} \mathrm{o}$ glucose was given at the rate of $10 \mathrm{ml}$. per hour $(2 \mathrm{oz}$. per pound of body weight per 24 hours). Intramuscular soluble insulin was continued, 5 or 10 units before feeds, according to the sugar levels in the blood and urine. After 72 hours of treatment the infant was improved and again sucked vigorously so intravenous fluids were discontinued.

Stabilization proved even more difficult than anticipated and it was found necessary to give insulin four-hourly before feeds. On a feeding regime of halfcream National Dried Milk, $105 \mathrm{ml}$., plus sugar, $5 \mathrm{~g}$., four-hourly, and 3 units of soluble insulin intramuscularly before feeds, hourly blood sugar levels over a 24-hour period fluctuated between $266 \mathrm{mg}$. and $16 \mathrm{mg}$. per $100 \mathrm{ml}$. Ketonuria was consistently absent even when the urine was loaded with sugar and the blood sugar was $600 \mathrm{mg}$. per $100 \mathrm{ml}$. In the first few weeks typical hypoglycaemic attacks occurred frequently. During several of these episodes blood sugar levels of less than $10 \mathrm{mg}$. per $100 \mathrm{ml}$. were recorded. On each occasion the attack was terminated when glucose, $10-20 \mathrm{~g}$. was given by stomach tube, save in one attack when 3 minims of subcutaneous adrenalin were required to restore consciousness.

When 5 weeks old she developed a mild anaemia ( $\mathrm{Hb}, 9 \cdot 1 \mathrm{~g}$.$) , doubtless aggravated by frequent blood$ sugar estimations, and a transfusion of $75 \mathrm{ml}$. of blood was given which raised the haemoglobin to $15.4 \mathrm{~g}$.

Despite these initial difficulties the baby gained weight rapidly and as her weight increased so the wrinkles were erased from her face. At the age of 8 weeks she was apparently well controlled on half-cream National Dried Milk, $120 \mathrm{ml}$., plus sugar, $10 \mathrm{~g}$., offered four-hourly (total calories 600), and 5 units of insulin before each feed. Her weight was then $3 \cdot 32 \mathrm{~kg}$. (7 lb. $5 \mathrm{oz}$ ). She seemed mentally normal and interested. At this point she was discharged from hospital on June 24, 1952, to abolish the risk of possible cross-infection. Her mother had mastered with admirable fortitude the technique of insulin injection. During the next two weeks she gained $0.61 \mathrm{~kg}$. (1 lb. $5 \mathrm{oz}$ ) but the strain on her mother was so severe that she was readmitted on July 4, 1952, in order that the 2 a.m. feed and injection could be omitted. She was then gradually changed from half to full-cream National Dried Milk and the insulin dosage was readjusted to 3 units of soluble before each four-hourly feed (five times daily). Her weight was then $4.55 \mathrm{~kg}$. ( $10 \mathrm{lb}$.) and she was again returned to her mother's care. During the next 14 weeks she was supervised as an out-patient, the insulin requirements remaining constant, while the feeds were increased gradually and solid foods introduced. At 20 weeks old, on December 7, 1952, the baby was readmitted for reassessment, and over four days' observation was found to have irregular glycosuria and blood sugar levels which fluctuated from $420 \mathrm{mg}$. to $40 \mathrm{mg}$. per $100 \mathrm{ml}$. The soluble insulin dosage was maintained at 3 units, five times daily. On January 7 , 1953, a glucose tolerance curve was carried out and gave the following results.

\begin{tabular}{lc}
\hline & Sugar Levels (mg. 100 ml.) \\
Before glucose & $80 \cdot 6$ \\
1 hour after glucose & $181 \cdot 8$ \\
1 hour after glucose & $196 \cdot 0$ \\
11 hours after glucose & $222 \cdot 2$ \\
2 hours after glucose & $235 \cdot 2$ \\
\hline
\end{tabular}

Now 8 months old (Fig. 2) the baby weighs $9.55 \mathrm{~kg}$. (21 lb.) and is on a normal mixed diet. The insulin dosage is unchanged. She is a happy and contented child reacting normally to her surroundings.

\section{Comments}

It seems probable that this child is an example of true pancreatic diabetes because of her dramatic and sustained improvement on insulin. Though born at full term, her birth weight

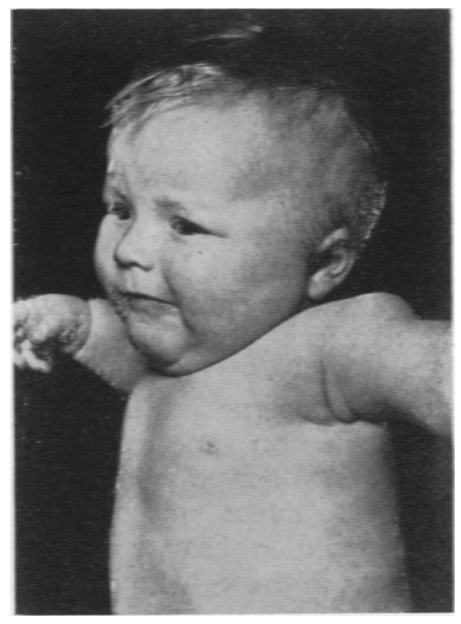

Fig. 2.-Appearance at the age of 8 months. was only $2 \cdot 4 \mathrm{~kg}$.

( $5 \mathrm{lb} .5 \mathrm{oz}$.). This might suggest that the disease was present in utero and that the mother's insulin proved insufficient for herself and the foetus.

In some of the cases reviewed the diagnosis of diabetes mellitus would appear to be in some doubt. For example, in the cases described by Ramsey (1926) and Lawrence and McCance (1931) there was a complete and spontaneous remission. In other cases, for example those described by Lewis and Eisenberg (1935) and Limper and Miller (1935), the glycosuria and high blood sugar levels were associated with an infection. In the present case there was no obvious clinical sign of infection. It is a striking fact that in all the reported cases. even those with the most marked glycosuria, there was no acetone in the urine. It is interesting to note that the present patient was alert and sucking when the blood sugar level was $706 \mathrm{mg}$. per $100 \mathrm{ml}$. 
In all the cases of diabetes during the neonatal period so far reported, excluding the two which recovered spontaneously, the mortality was $100 \%$ before the age of 6 months. The immediate prognosis of the patient here reported seems now to be good. The ultimate prognosis cannot be assessed.

\section{Summary}

Seven cases of diabetes mellitus with the onset in the neonatal period are reviewed.

A patient diagnosed at 17 days, treated with insulin and thriving at 8 months, is described.
Thanks are due to Dr. J. H. Hutchison for permission to publish this case and for his advice and criticism.

REFERENCES

Brodribb, H. S., McMurray, J. and Scott, L. G. (1952). Brit. med. J., 1. 1060 .

Cuno, F. (1910). Jb. Kinderheilk., 71. 623.

Device, J. (1938). Archives of Disease in Childhood, 13, 189.

Kitselk, J. F. (1852). Jb. Kinderheilk, 18. 313.

Lawrence, R. D. and McCance, R. A. (1931). Archives of Disease in Childhood, 6, 343.

Lewis, E. and Eisenberg, H. (1935). Amer. J. Dis. Child., 49, 408.

Limper, M. A., and Milker, A. J. (1935). Ibid., 50. 1216.

Ramsey, W. R. (1926. Trans. Amer. pediat. Soc., 38, 100.

Schwartzman, J., Crusius, M. E. and Beirne, D. P. (1947). Amer. J. Dis. Child., 74, 587 . 